\title{
PENENTUAN HARGA OPSI ASIA DENGAN RATA-RATA GEOMETRIK MELALUI PENDEKATAN BLACK-SCHOLES
}

\author{
Utin Indah Lestari, Evy Sulistianingsih, Nurfitri Imro'ah
}

\begin{abstract}
INTISARI
Opsi Asia adalah opsi yang payoff-nya bergantung pada rata-rata harga aset selama masa berlaku opsi. Opsi Asia digemari investor karena dapat mengurangi kemungkinkan kerugian dan meningkatkan keuntungan pada saat-saat akhir menjelang waktu jatuh tempo opsi (maturity). Tujuan dari penelitian ini adalah menentukan harga opsi Asia menggunakan rata-rata geometrik. Harga opsi Asia dapat ditentukan dengan menggunakan rata-rata geometrik melalui pendekatan Black-Scholes. Data yang digunakan dalam penelitian ini adalah data Microsoft Corporation periode 25 September 2017 sampai 25 September 2018 setelah itu ditentukan indikator $\hat{\mu}, \hat{\sigma}^{2}, \hat{d}_{1}$ dan $\hat{d}_{2}$, return saham $\left(R_{t}\right)$, dan volatilitas $(\sigma)$. Indikator tersebut digunakan untuk menentukan harga opsi Asia. Berdasarkan hasil perhitungan dengan menggunakan rata-rata geometrik melalui pendekatan BlackScholes, didapat opsi jual tipe Asia memiliki harga yang lebih rendah dibandingkan dengan harga opsi jual pasaran. Nilai hitung inilah yang dapat menjadi acuan investor dalam menjual opsi. Nilai hitung yang diperoleh investor lebih baik menjual opsi tersebut karena opsi di pasar lebih tinggi dari harga opsi dengan rata-rata geometrik sehingga investor dapat memperoleh keuntungan.
\end{abstract}

Kata Kunci: Opsi Asia, Rata-Rata Geometrik, Proses Stokastik, Black-Scholes

\section{PENDAHULUAN}

Di dunia pasar modal, investor berusaha untuk meminimalisir kerugian dalam penjualan ataupun pembelian aset. Salah satu produk investasi yang menarik dan banyak digunakan adalah saham. Investor memiliki pilihan untuk membeli saham secara langsung untuk diperdagangkan pada pasar keuangan atau membeli derivatif dari saham tersebut. Derivatif ini diperdagangkan karena dianggap menguntungkan para investor yang ingin bermain di pasar saham. Salah satu produk pasar derivatif yang banyak diperjualbelikan adalah opsi.

Opsi adalah suatu jenis kontrak antara dua pihak dimana satu pihak memberi hak kepada pihak lain untuk membeli atau menjual aset tertentu pada harga dan periode tertentu [1]. Dengan adanya opsi, investor memiliki pilihan untuk menempatkan dananya dalam berbagai jenis instrumen yang bertujuan mengurangi tingkat risiko [2].

Terdapat opsi yang dimana payoff tidak hanya bergantung pada harga aset pada saat pelaksanaan, tetapi juga bergantung pada harga aset selama masa berlaku opsi. Opsi ini dikenal juga dengan opsi eksotik. Contoh opsi eksotik adalah opsi Asia [3].

Opsi Asia adalah opsi yang nilai payoff opsinya bergantung pada rata-rata saham selama masa opsi berlangsung. Penentuan harga opsi Asia dapat dilakukan dengan menggunakan rata-rata geometrik. Karakteristik dari rata-rata geometrik adalah ketika harga saham berdistribusi lognormal, rata-rata geometrik harga sahamnya juga berdistribusi lognormal. Karena karakteristik tersebut, ratarata geometrik memenuhi salah satu asumsi dari model Black-Scholes yaitu harga saham yang digunakan berdistribusi lognormal. Sehingga, untuk menentukan harga opsi Asia menggunakan ratarata geometrik dapat dilakukan dengan mendekati kerangka Black-Scholes [2].

Tujuan dalam penelitian ini untuk menentukan harga opsi jual tipe Asia menggunakan rata-rata geometrik melalui pendekatan Black-Scholes. Batasan masalah dalam penelitian ini, yaitu waktu pengeksekusian opsi menggunakan opsi Asia, aset dasar yang digunakan berupa saham, dan harga opsi yang dihitung pada penelitian ini adalah opsi jual. 
Penelitian ini dilakukan dengan menggunakan saham dari perusahaan Microsoft Corporation yang diakses langsung dari http://www.finance.yahoo.com. Data harga saham penutupan yang digunakan merupakan data harian yang diambil mulai dari 25 September 2017 sampai dengan 25 September 2018. Dilanjutkan dengan melengkapi informasi seperti harga saham awal, waktu jatuh tempo, dan suku bunga bebas risiko dan dilanjutkan dengan mencari nilai return saham. Asumsi dari model pergerakan saham adalah return yang dihasilkan berdistribusi Normal, karena itu dilakukan pengujian menggunakan uji Kolmogorof-Smirnov. Apabila return tidak berdistribusi Normal, maka proses tidak dapat dilanjutkan dan dipilih kembali data saham yang baru. Tahap selanjutnya dicari volatilitas aset, menentukan indikator $\hat{\mu}, \hat{\sigma}^{2}, \hat{d}_{1}$ dan $\hat{d}_{2}$. Kemudian, didapat harga opsi jual yang akan dibandingkan dengan harga opsi jual di pasar.

\section{RATA-RATA GEOMETRIK}

Payoff pada opsi Asia bergantung kepada rata-rata harga saham. Oleh karena itu harga saham pada saat jatuh tempo, yaitu $S(t)$ dapat disubstitusikan dengan rata-rata geometrik yang dinotasikan sebagai berikut [2].

$$
G=\left(\prod_{i=1}^{n} S\left(t_{i}\right)\right)^{\frac{1}{n}}
$$

dengan $t_{i}>0$ adalah pembobotan dari harga yang relevan, $S\left(t_{i}\right)$ adalah harga aset pada saat $t_{i}$, dan $n$ adalah banyaknya harga aset.

\section{RETURN SAHAM DAN VOLATILITAS SAHAM}

Return saham dapat diartikan sebagai tingkat imbal hasil (tingkat keuntungan) yang diperoleh sebagai akibat dari investasi yang dilakukan. Nilai dari return bisa positif maupun negatif tergantung kondisi real dari aset investasi. Sebagai ukuran return majemuk digunakan continuously compounding return. Return jenis ini lebih sering digunakan dalam analisis keuangan karena sifat-sifatnya yang mengikuti distribusi Normal. Continuously compounding return diformulasikan sebagai berikut[1]:

$$
R(t)=\ln \left(\frac{S(t)}{S(t-1)}\right)
$$

dengan $S(t)$ adalah harga saham saham pada waktu $t, S(t-1)$ adalah harga saham per lembar saham pada waktu $(t-1)$, dan $R(t)$ adalah return harga saham pada waktu $t$.

Volatilitas return saham yang dinyatakan dengan $\sigma$ merupakan deviasi standar dari return saham pada periode tahunan. Volatilitas ini digunakan untuk mengukur tingkat risiko dari suatu saham. Nilai volatilitas berada pada interval yaitu $0 \leq \sigma<\infty$. Nilai volatilitas yang tinggi menunjukkan bahwa harga saham berubah (naik dan turun) dengan range yang sangat lebar. Sedangkan volatilitas dikatakan rendah jika harga saham jarang berubah atau cenderung konstan.

Salah satu metode untuk mengestimasi volatilitas return saham adalah volatilitas historis, yaitu volatilitas yang dihitung berdasarkan pada harga-harga masa lalu. Hal ini dengan anggapan bahwa perilaku harga saham di masa lalu dapat mencerminkan perilaku harga saham di masa mendatang [1].

$$
\sigma=\sqrt{\text { jumlah hari perdagangan } \times\left[\frac{\sum_{t=1}^{n}(R(t)-\overline{R(t)})^{2}}{n-1}\right]}
$$


dengan $\sigma$ adalah nilai volatilitas return saham, $R(t)$ adalah return harga saham pada waktu $t$, $\bar{R}(t)$ adalah rata-rata saham harian dan $n$ adalah jumlah saham.

\section{UJI KOLMOGOROF-SMIRNOV RETURN SAHAM}

Salah satu teknik yang digunakan untuk menguji apakah data berdistribusi Normal adalah uji Kolmogorof-Smirnov (K-S). Konsep dasar uji normalitas $(K-S)$ adalah membandingkan distribusi teoritik dan distribusi empirik (observasi) berdasarkan frekuensi kumulatif.

Misalkan $X_{1}, X_{2} \ldots X_{n}$ adalah sampel random berukuran $n$ dari suatu populasi dengan fungsi distribusi $F(x)$ dan $F_{n}(x)$ adalah frekuensi kumulatif. Andaikan $F_{0}(x)$ adalah suatu fungsi distribusi tertentu dan akan diuji [5]:

$$
\begin{array}{ll}
\mathrm{H}_{0}: F(x)=F_{0}(x) \text { untuk semua } x & \text { (data berdistribusi tertentu) } \\
\mathrm{H}_{1}: F(x) \neq F_{0}(x) \text { untuk suatu } x & \text { (data tidak berdistribusi tertentu) }
\end{array}
$$

Uji Kolmogorof-Smirnov menggunakan statistik uji:

$$
T=\sup _{-\infty<x<\infty}\left|F_{n}(x)-F_{0}(x)\right|
$$

Kesimpulan yang diambil adalah $\mathrm{H}_{0}$ ditolak jika nilai $T>T_{n, \alpha} . T_{n, \alpha}$ nilai kritik dari statistik $T$.

\section{MODEL BLACK-SCHOLES}

Penetapan harga opsi mulai berkembang sejak dirumuskan oleh Fisher Black dan Myron Scholes pada tahun 1972 yang dikenal dengan model Black-Scholes. Model Black-Scholes ini juga digunakan untuk menilai dana bertujuan ganda, serta untuk meningkatkan opsi barang komoditi, kontrak berjangka dan kontrak akan datang [6]. Persamaan Black-Scholes untuk menentukan harga opsi jual Asia adalah sebagai berikut [7].

$$
P=\max (K-S, 0)
$$

Persamaan (5) digunakan untuk membentuk persamaan baru dalam menentukan harga opsi Asia menggunakan rata-rata geometrik melalui pendekatan Black-Scholes.

\section{KARAKTERISTIK RATA-RATA GEOMETRIK DALAM OPSI ASIA}

Karakteristik dari rata-rata geometrik adalah ketika harga saham berdistribusi lognormal dan rata-rata geometrik harga sahamnya juga berdistribusi lognormal. Rata-rata geometrik harga saham berdistribusi lognormal adalah sebagai berikut.

$$
\ln \left[\left(\prod_{i=1}^{n} S\left(t_{i}\right)\right)^{\frac{1}{n}}\right] \square N\left(\ln S(0)+\left(\hat{\mu}-\frac{1}{2} \hat{\sigma}^{2}\right) T, \hat{\sigma}^{2} T\right)
$$

Karakteristik dari rata-rata geometrik menunjukkan bahwa logaritma rata-rata geometrik harga saham berdistribusi normal, yang berarti bahwa rata-rata geometrik harga saham berdistribusi lognormal. Karena rata-rata geometrik berdistribusi lognormal, maka penentuan harga opsi Asia menggunakan rata-rata geometrik dapat didekati ke kerangka Black-Scholes. Maka selanjutnya akan ditentukan harga opsi Asia menggunakan rata-rata geometrik.

\section{PEMBENTUKAN FORMULA BLACK-SCHOLES UNTUK MENENTUKAN HARGA OPSI JUAL ASIA DENGAN MENGGUNAKAN RATA-RATA GEOMETRIK}

Pembentukan formula untuk menentukan harga opsi jual tipe Asia dengan menggunakan ratarata geometrik akan merujuk berdasarkan model Black-Scholes opsi jual. Formula opsi jual adalah sebagai berikut. 


$$
\begin{aligned}
P & =e^{-r T} E[\text { payoff }] \\
P & =e^{-r T} E\left[\max \left(K-\left(\prod_{i=1}^{n} S\left(t_{i}\right)\right)^{\frac{1}{n}}, 0\right)\right] \\
& =e^{-r T} E[\max (K-G, 0)]
\end{aligned}
$$

Dengan menggunakan sifat ekspektasi, maka harga opsi pada Persamaan (7) dapat ditulis sebagai berikut.

$$
\begin{aligned}
P & =e^{-r T} \int_{-\infty}^{\infty} \max (K-g, 0) p(g) d g \\
& =e^{-r T}\left\{\int_{0}^{K} \max (K-g, 0) p(g) d g+\int_{K}^{\infty} \max (K-g, 0) p(g) d g\right\} \\
& =e^{-r T}\left\{\int_{0}^{K} \max (K-g, 0) p(g) d g+0\right\} \\
& =e^{-r T} \int_{0}^{K} \max (K-g, 0) p(g) d g
\end{aligned}
$$

dengan $p(g)$ adalah $p d f$ dari variabel random $G$, sebagai berikut [2]

$$
p(g)=\frac{1}{g \hat{\sigma} \sqrt{2 \pi T}} \exp \left(-\frac{1}{2}\left(\frac{\ln g-\ln S(0)-\left(\hat{\mu}-\frac{1}{2} \hat{\sigma}^{2}\right) T}{\hat{\sigma} \sqrt{T}}\right)^{2}\right)
$$

Persamaan (8) dapat diubah bagian integralnya menjadi

$$
\begin{aligned}
P & =e^{-r T} \int_{0}^{K}(K-g) p(g) d g \\
& =K e^{-r T} \int_{0}^{K} p(g) d g-e^{-r T} \int_{0}^{K} g p(g) d g \\
& =\text { I - II }
\end{aligned}
$$

1) Solusi untuk Persamaan I ditentukan dengan cara mensubstitusikan Persamaan (9) ke Persamaan I, sehingga.

$$
K e^{-r T} \int_{0}^{K} p(g) d g=K e^{-r T} \int_{0}^{K} \frac{1}{g \hat{\sigma} \sqrt{2 \pi T}} \exp \left(-\frac{1}{2}\left(\frac{\ln g-\ln S(0)-\left(\hat{\mu}-\frac{1}{2} \hat{\sigma}^{2}\right) T}{\hat{\sigma} \sqrt{T}}\right)^{2}\right) d g
$$

Pada Persamaan (11) variabel $g$ dimisalkan menjadi variabel $u$, maka didapat

$$
u=\frac{\ln g-\ln S(0)-\left(\hat{\mu}-\frac{1}{2} \hat{\sigma}^{2}\right) T}{\hat{\sigma} \sqrt{T}}
$$

Diferensialkan Persamaan (12) terhadap g, maka akan didapat

$$
d g=g \hat{\sigma} \sqrt{T} d u
$$


dengan menggunakan transformasi pada persamaan (12) dan (13), maka Persamaan (11) akan diperoleh sebagai berikut.

$$
K e^{-r T} \int_{0}^{K} p(g) d g=K e^{-r T} \int_{-\infty}^{\frac{-\left(\ln S(0)-\ln K+\left(\hat{\mu}-\frac{1}{2} \hat{\sigma}^{2}\right) T\right)}{\hat{\sigma} \sqrt{T}}} \frac{1}{\sqrt{2 \pi}} \exp \left(-\frac{1}{2} u^{2}\right) d u
$$

Pada Persamaan (14) dimisalkan $\hat{d}_{2}=\frac{\ln S(0)-\ln K+\left(\hat{\mu}-\frac{1}{2} \hat{\sigma}^{2}\right) T}{\hat{\sigma} \sqrt{T}}$, maka Persamaan (14) dapat dituliskan kembali menjadi

$$
\begin{aligned}
K e^{-r T} \int_{0}^{K} p(g) d g & =K e^{-r T} \int_{-\infty}^{-\hat{d}_{2}} \frac{1}{\sqrt{2 \pi}} \exp \left(-\frac{1}{2} u^{2}\right) d u \\
& =K e^{-r T} N\left[-\hat{d}_{2}\right]
\end{aligned}
$$

Jadi, dapat disimpulkan bahwa solusi dari Persamaan I adalah

$$
K e^{-r T} N\left[-\hat{d}_{2}\right]
$$

dengan $N\left[-\hat{d}_{2}\right]$ adalah $c d f$ dari distribusi normal dari $-\hat{d}_{2}$

2) Solusi untuk Persamaan II ditentukan dengan cara mensubstitusikan Persamaan (9) ke Persamaan II, sehingga

$$
\int_{0}^{K} g p(g) d g=\int_{0}^{K} g \frac{1}{g \hat{\sigma} \sqrt{2 \pi T}} \exp \left(-\frac{1}{2}\left(\frac{\ln g-\ln S(0)-\left(\hat{\mu}-\frac{1}{2} \hat{\sigma}^{2}\right) T}{\hat{\sigma} \sqrt{T}}\right)^{2}\right) d g
$$

Mengubah variabel $g$ menjadi variabel $b$ dengan menggunakan

$$
\begin{array}{r}
b=\ln g, \text { maka } g=e^{b} \\
d b=\frac{1}{g} d g \rightarrow d g=g d b \\
\rightarrow d g=e^{b} d b
\end{array}
$$

Dengan menggunakan transformasi pada persamaan (17), maka Persamaan (16) akan berubah menjadi

$$
\int_{0}^{K} g p(g) d g=\int_{-\infty}^{\ln K} \frac{1}{\hat{\sigma} \sqrt{2 \pi T}} \exp \left(b-\frac{1}{2}\left(\frac{b-\ln S(0)-\left(\hat{\mu}-\frac{1}{2} \hat{\sigma}^{2}\right) T}{\hat{\sigma} \sqrt{T}}\right) d b\right.
$$

Pada Persamaan (18) dimisalkan

$$
H=b-\frac{1}{2}\left(\frac{b-\ln S(0)-\left(\hat{\mu}-\frac{1}{2} \hat{\sigma}^{2}\right) T}{\hat{\sigma} \sqrt{T}}\right)^{2}
$$

Persamaan (19) dimodifikasi sehingga didapat sebagai berikut. 


$$
H=\frac{1}{2} \underbrace{\left(\frac{b-\left(\ln S(0)+\left(\hat{\mu}+\frac{1}{2} \hat{\sigma}^{2}\right) T\right)}{\hat{\sigma} \sqrt{T}}\right)}_{v}+\ln S(0)+\hat{\mu} T
$$

diferensialkan variabel $v$ sehingga menjadi sebagai berikut.

$$
\begin{aligned}
v \hat{\sigma} \sqrt{T} & =b-\left(\ln S(0)+\left(\hat{\mu}+\frac{1}{2} \hat{\sigma}^{2}\right) T\right) \\
b & =v \hat{\sigma} \sqrt{T}+\left(\ln S(0)+\left(\hat{\mu}+\frac{1}{2} \hat{\sigma}^{2}\right) T\right) \\
d b \quad & =\hat{\sigma} \sqrt{T} d v
\end{aligned}
$$

Maka diperoleh solusi untuk persamaan II adalah sebagai berikut

$$
\begin{aligned}
& \int_{0}^{K} g p(g) d g=\int_{-\infty}^{\frac{\ln K-\ln S(0)-\left(\hat{\mu}+\frac{1}{2} \hat{\sigma}^{2}\right) T}{\hat{\sigma} \sqrt{T}}} \frac{1}{\hat{\sigma} \sqrt{2 \pi T}} \exp \left(-\frac{1}{2} v^{2}+\ln S(0)+\hat{\mu} T\right) \hat{\sigma} \sqrt{T} d v \\
&-\left(\frac{\ln S(0)-\ln K+\left(\hat{\mu}+\frac{1}{2} \hat{\sigma}^{2}\right) T}{\hat{\sigma} \sqrt{T}}\right) \\
& \int_{-\infty} \frac{1}{\sqrt{2 \pi}} e^{-\frac{1}{2} v^{2}} e^{\ln S(0)} e^{\hat{\mu} T} d v
\end{aligned}
$$

Pada Persamaan (22) dimisalkan $\hat{d}_{1}=\frac{\ln S(0)-\ln K+\left(\hat{\mu}+\frac{1}{2} \hat{\sigma}^{2}\right) T}{\hat{\sigma} \sqrt{T}}$, maka Persamaan (22) dapat dituliskan kembali menjadi

$$
\begin{aligned}
\int_{0}^{K} g p(g) d g & =\int_{-\infty}^{-\hat{d}_{1}} \frac{1}{\hat{\sigma} \sqrt{2 \pi T}} e^{-\frac{1}{2} v^{2}} e^{\ln S(0)} e^{\hat{\mu} T} d b \\
& =S(0) e^{\hat{\mu} T} \int_{-\infty}^{-\hat{d}_{1}} \frac{1}{\sqrt{2 \pi}} e^{-\frac{1}{2} v^{2}} d v \\
& =S(0) e^{\hat{\mu} T} N\left[-\hat{d}_{1}\right]
\end{aligned}
$$

Jadi, dapat disimpulkan bahwa solusi dari Persamaan II adalah

$$
e^{-r T} S(0) e^{\hat{\mu} T} N\left[-\hat{d}_{1}\right]
$$

dengan $N\left[-\hat{d}_{1}\right]$ adalah $c d f$ dari distribusi normal dari $-\hat{d}_{1}$.

Setelah mendapatkan solusi dari Persamaan I dan II, substitusikan Persamaan (15) dan (23) ke dalam Persamaan (10), sehingga diperoleh

$$
\begin{aligned}
P & =K e^{-r T} \int_{0}^{K} p(g) d g-e^{-r T} \int_{0}^{K} g p(g) d g \\
& =K e^{-r T} N\left[-\hat{d}_{2}\right]-e^{-r T} S(0) e^{\hat{\mu} T} N\left[-\hat{d}_{1}\right] \\
& =e^{-r T}\left(K N\left[-\hat{d}_{2}\right]-S(0) e^{\hat{\mu} T} N\left[-\hat{d}_{1}\right]\right)
\end{aligned}
$$


dimana,

$$
\begin{aligned}
& \hat{d}_{1}=\frac{\ln \left(\frac{S(0)}{K}\right)+\left(\hat{\mu}+\frac{1}{2} \hat{\sigma}^{2}\right) T}{\hat{\sigma} \sqrt{T}} \\
& \hat{d}_{2}=\frac{\ln \left(\frac{S(0)}{K}\right)+\left(\hat{\mu}-\frac{1}{2} \hat{\sigma}^{2}\right) T}{\hat{\sigma} \sqrt{T}} \\
& \hat{\mu}=\frac{1}{2} \hat{\sigma}^{2}+\left(r-\frac{1}{2} \sigma^{2}\right) \frac{n+1}{2 n} \\
& \hat{\sigma}^{2}=\frac{\sigma^{2}(n+1)(2 n+1)}{6 n^{2}}
\end{aligned}
$$

\section{HASIL DAN PEMBAHASAN}

Data yang digunakan dalam penelitian ini adalah saham dari perusahaan Microsoft Corporation yang diakses langsung dari http://www.finance.yahoo.com. Data harga saham penutupan yang digunakan merupakan data harian yang diambil mulai dari 25 September 2017 sampai dengan 25 September 2018. Data harga saham berjumlah 251, dengan harga minimum dan maksimum sebesar $\$ 73,26$ dan $\$ 114,26$.

Langkah awal dari pengerjaan adalah uji normalitas menggunakan uji Kolmogorof-Smirnov untuk melihat normalitas distribusi data return saham. Kenormalan data return adalah syarat dalam mengestimasi volatilitas aset. Hasil uji normalitas yang dilakukan didapat nilai $P$-Value dari Kolmogorof-Smirnov return Saham $(0,052)>\alpha(0,05)$. Sehingga dapat disimpulkan bahwa data return saham berdistribusi normal. Kemudian dilanjutkan dengan mencari nilai volatilitas aset yang dihitung dari estimasi standar deviasi data return dari nilai total aset perusahaan. Nilai volatilitas yang diperoleh adalah adalah sebesar 0,23 atau $23 \%$.

Indikator yang digunakan dalam perhitungan yaitu harga saham awal $S(0): 114,26(\$)$, waktu jatuh tempo adalah 25 Oktober 2018 yang berarti $T=\frac{30}{365}=0,822$. Tingkat suku bunga bebas resiko $(r)=2,25 \%$, dan harga pelaksaan $(K): 90,95,96,97,97,5(\$)$.

Perhitungan harga opsi jual dengan menggunakan rata-rata geometrik melalui pendekatan Black-Scholes untuk harga pelaksanaan 90. Nilai berturut dari $\hat{\sigma}^{2}, \hat{\mu}, \hat{d}_{1}$, dan $\hat{d}_{2}$ adalah sebesar 0,017, $0,0071,6,412$, dan 6,375 . Selanjutnya dapat dicari nilai $N\left[-\hat{d}_{1}\right]$ dan $N\left[-\hat{d}_{2}\right]$ dengan menggunakan bantuan perintah NORMSDIST pada software Microsoft Excel. Kemudian akan dihitung harga opsi Asia pada opsi jual dengan rata-rata geometrik melalui pendekatan Black-Scholes. Hasil perhitungan harga opsi jual dengan menggunakan rata-rata geometrik melalui pendekatan Black-Scholes dibandingkan dengan harga opsi jual di pasar. Hasil tersebut disajikan pada Tabel 1 sebagai berikut.

Tabel 1 Perbandingan Harga Opsi Jual dengan Rata-Rata Geometrik Melalui Pendekatan BlackScholes dengan Harga Opsi Jual di Pasar

\begin{tabular}{lcc}
\hline \multicolumn{1}{c}{ Harga Kesepakatan } & Harga Opsi Jual & Harga Opsi Jual di Pasar \\
\hline$\$ 90$ & $\$ 4,595 \times 10^{-11}$ & $\$ 0,03$ \\
$\$ 95$ & $\$ 2,738 \times 10^{-7}$ & $\$ 0,01$ \\
$\$ 96$ & $\$ 1,173 \times 10^{-6}$ & $\$ 0,03$ \\
$\$ 97$ & $\$ 4,610 \times 10^{-6}$ & $\$ 0,02$ \\
$\$ 97,5$ & $\$ 8,853 \times 10^{-6}$ & $\$ 0,02$ \\
\hline
\end{tabular}


Berdasarkan Tabel 1 dapat dilihat pada bahwa semakin tinggi harga kesepakatan maka harga opsi jual semakin besar. Harga opsi jual pada harga kesepakatan 90, 95, 96, 97, dan 97,5(\$) memiliki harga yang lebih rendah dibandingkan dengan harga opsi jual pasaran. Nilai hitung yang diperoleh adalah investor lebih baik menjual opsi tersebut karena opsi di pasar lebih tinggi dari harga opsi dengan rata-rata geometrik sehingga investor dapat memperoleh keuntungan.

\section{KESIMPULAN}

Berdasarkan pembahasan penelitian ini dapat disimpulkan bahwa diperoleh harga opsi jual tipe Asia menggunakan rata-rata geometrik dengan pendekatan model Black-Scholes. Harga opsi Asia yang diperoleh dengan data pergerakan saham Microsoft Corporation pada tanggal 25 September 2017 sampai 25 September 2018 dengan harga kesepakatan 90, 95, 96, 97, dan 97,5(\$) adalah $4,595 \times 10^{-11}, 2,738 \times 10^{-7}, 1,173 \times 10^{-6}, 4,610 \times 10^{-6}$, dan $8,853 \times 10^{-6}(\$)$. Harga yang diperoleh menjadi acuan investor dalam menjual opsi, dimana investor lebih baik menjual opsi tersebut tersebut karena opsi di pasar lebih tinggi dari harga opsi dengan rata-rata geometrik sehingga investor dapat memperoleh keuntungan

\section{DAFTAR PUSTAKA}

[1] Hull JC. Option, Future, and Other Derivatives 5th Edition. Pearson Education, Inc, New Jersey: 216-266; 2003.

[2] Harwella S. Penggunaan Rata-Rata Aritmetika dengan Approksimasi Curran Dalam Menentukan Harga Opsi Asia. Padang : Jurnal Matematika UNAND. 2014; Vol. 3 No. 4:70-77.

[3] Hastuti ES, Dodi D. Penggunaan Rata-Rata Geometrik dalam Menentukan Harga Opsi Asia. Padang: Jurnal Matematika UNAND. 2014; Vol. 3 No. 2 Hal. 44-52.

[4] Curran M. Valuing Asian and Portfolio Options by Conditioning on the Geometric Price, Journal of Management Science. The Institute of Management Science, 1994. New York: 17051711.

[5] Siegel S. Nonparametric Statistics: For The Behavioral Sciences. MeGraw-Hill Book Company Inc, New York; 1956.

[6] Yosmar S. Penetapan Harga Opsi Saham dengan Menggunakan Model Black-Scholes. Sumatera Barat: Jurnal Sains, 2012; Vol. IV. No.1: 76-83.

[7] Higham DJ. An Introdustion to Financial Option Valuation, Mathematics, Stochastics and Computation. Cambridge University Press, Cambridge: 45-120; 2004.

UTIN INDAH LESTARI

EVY SULISTIANINGSIH

NURFITRI IMRO'AH
: FMIPA Untan Pontianak, utin.indah.18@gmail.com

: FMIPA Untan Pontianak, evysulistianingsih@math.untan.ac.id

: FMIPA Untan Pontianak, nurfitriimroah18@gmail.com 